NISSUNA UMANA INVESTIGAZIONE SI PUO DIMANDARE VERA SCIENZIA S'ESSA NON PASSA PER LE MATEMATICHE DIMOSTRAZIONI LEONARDO DA VINCI

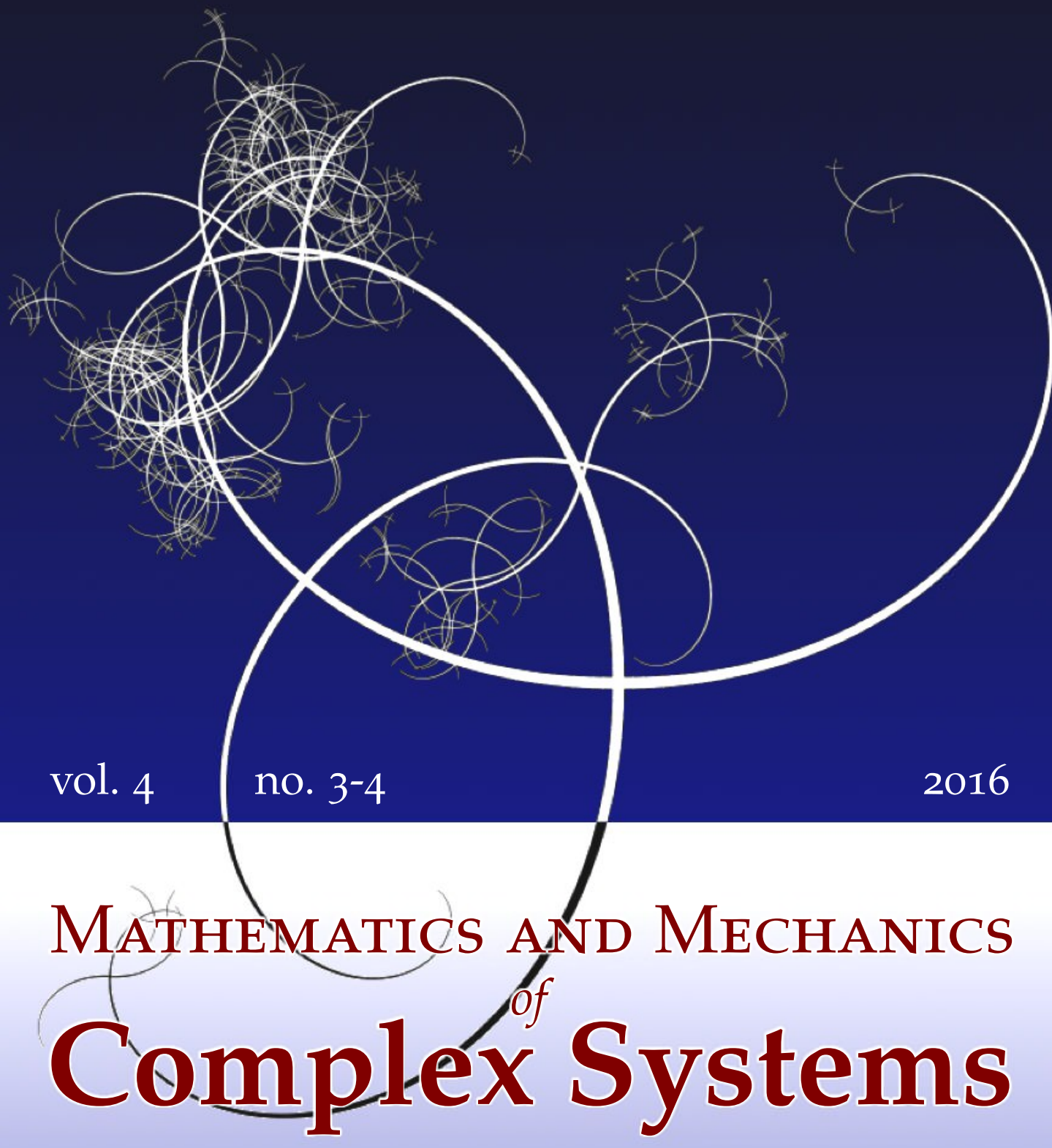

GiOVANNI GALLAVOTTI

LUCIO RUSSO: PROBABILITY THEORY AND CURRENT INTERESTS 


\title{
LUCIO RUSSO: PROBABILITY THEORY AND CURRENT INTERESTS
}

\author{
Giovanni Gallavotti
}

We review Russo's original contributions to various fields of probability theory and his parallel interest in history and the influence of Hellenistic science.

The work of Lucio Russo started in the early 1970s. I met him in Naples, and it became immediately clear that I had met a very young and very promising scientist. And I had the privilege to collaborate with him on the problem of the isomorphism between Ising model equilibrium probability distributions in the convergence domain of the cluster expansion and Bernoulli schemes of the same entropy [di Liberto et al. 1973].

Soon afterwards I left Naples, but I continued to follow his work. His study of the isomorphism problem was pursued and led to a major result on coding theory; he proved the existence of a finitary code between the simplest Markov process (the one-dimensional Ising model with nearest neighbor interaction) and the Bernoulli shift with the same entropy [Monroy and Russo 1975]. I saw the impact that this work had on the complete solution of the general construction [Keane and Smorodinsky 1977] of a code of a Markov chain into a Bernoulli shift and the recognition that it received.

To carry out this work he learned in a short time the deep and innovative work of Ornstein on the theory of Bernoulli shifts and was able to give a substantial contribution to the applications of the theory.

He rapidly became internationally known as a leading probabilist, contributing to advances on the percolation problem beginning with studying the attractive Ising model, establishing a close relation between the existence of infinite clusters of spin + or - and the presence of spontaneous magnetization in the extremal states $\mu_{ \pm}$, with the remarkable result that in general dimension the spontaneous magnetization in the state $\mu_{+}$or $\mu_{-}$yields a lower bound to the percolation probability (i.e., existence of infinite clusters of + or - , respectively). Furthermore, in $2 \mathrm{D}$ coexistence of infinite clusters of both types was excluded in all pure states [Coniglio et al. 1976; 1977].

\section{Communicated by Francesco dell'Isola.}

Keywords: percolation, probability, Ising model, phase coexistence, coding theory, Markov processes, Hellenistic science, infinite clusters. 
In the course of about three years, he worked intensely on percolation (in Bernoulli sites distribution as well as in Ising model equilibria), employing the FKG and GHS inequalities, first extending a result by Harris on critical percolation and proving that mean size of the finite clusters is finite [Russo 1978]. This led, in a subsequent work, to the proof, in the case of percolation on $\mathbb{Z}^{2}$, of the Essam-Sykes conjecture on the critical probabilities of two "matching graphs" $\left(p_{c}+p_{c}^{*}=1\right)$ [Russo 1981].

A result on the difficult problem of the (site) percolation in $\mathbb{Z}^{3}$ followed after a series of studies (mostly in 2D). The first was on a proof that in 2D-Ising there is a unique infinite cluster for $T \leq T_{c}$ and that the critical point and the percolation point coincide (different from their already known noncoincidence in 3D) [Coniglio et al. 1976; 1977]; the smoothness, away from the critical point, of the 2D percolation probability dependence on the occupation probability followed [Russo 1978]; the Essam-Sykes conjecture was then proved [Russo 1981], obtaining also (on $\mathbb{Z}^{2}$ ) that the site percolation probability is a continuous function of the site probability $p$. Finally the methods, always based on inequalities known in statistical mechanics and on several extensions developed in Russo's works, have been applied to the 3D-percolation and to the 3D-Ising model: the critical site percolation is proved to be $<\frac{1}{2}$, and in 3D-Ising at high temperature (and small field), coexisting infinite clusters are shown to be possible [Campanino and Russo 1985].

The first results on percolation paved the way for a groundbreaking result, based on the Ising model inequalities and relying also on ideas developed in the first few percolation papers (which will also be further developed in the later works), on the uniqueness of the translation-invariant Gibbs states in the two-dimensional Ising model [Russo 1979]. It introduced a fresh view and a new method on the uniqueness problem of the pure phases and proved that the states that were translationinvariant in one direction were necessarily invariant under all translations. Immediately after publication of his work, his result has been basic to the final solution of the longstanding conjecture about the translation invariance of the equilibrium states of the Ising model at all temperature and field values (independently in [Higuchi 1981; Aizenman 1980]).

Percolation continued to be the focus of his interests; for the site percolation problem, with site probability $p$, Russo proved that the probability of a given positive event $A$ measurable at infinity (or close enough to be such) passes from 0 to 1 as $p$ grows through a value $p_{0}$, an extension of the Hewitt-Savage zero-one law [Russo 1982]. This result was also shown to be useful in determining, by a new method, the relation $p_{c}+p_{c}^{*}=1$ for the critical percolations on the square lattice and its matching lattice.

A theory of a different kind of percolation, the (independently occupied with probability $p$ ) plaquettes percolation on $\mathbb{Z}^{d}, d \geq 3$, is studied. It was shown that in $d=3$ the existence of a phase transition in the dependence of the probability that 
the occupied plaquettes form a surface with given boundary decays exponentially with the area of the surface for small $p$ but at high plaquettes density, i.e., $p$ close to 1 , the probability decays with the length of the boundary. The result, found in [Aizenman et al. 1983], is obtained employing also the duality between plaquette percolation and bond percolation, and the sharpness of the transition (as a function of $p$ ) is related to a conjecture on the $3 \mathrm{D}$ bond percolation.

The problem of the uniqueness of infinite percolating clusters is then reexamined first in the case of Bernoulli percolation and then in the 2D case of rather general site distribution, subject to conditions of translation ergodicity in each direction and to the monotonicity of $\mu(F \cap G) \geq \mu(F) \mu(G)$ [Gandolfi et al. 1988a; 1988b].

The attention to inequalities, an essential feature of most if not all of Russo's works, has generated a work on new inequalities related to the FKG inequalities which have new applications to a variant of the Ising model, the "plaquette model" [Cammarota and Russo 1991], considered in certain gauge theories.

Russo has also contributed to other fields of mathematics like dynamical systems and analysis, with the same uncompromising attention to mathematical rigor transpiring from his probability works, providing insights and suggestions in the normal seminars held in the departments where he has been a member [Franceschini and Russo 1981; 1983].

All the above results were obtained by Russo working alone or in collaboration with other scientists. His sharp understanding of the probability theory of Bernoulli distributions or of Ising distributions as always been an essential contribution. At the end of the 1980s, Russo's main interests switched to the history of science, revealing a less known aspect of his personality which had remained hidden to most of his colleagues. In a sense he really concentrated on the classic achievements from the Hellenistic science to the 1600s.

This choice left little room to continue developing probability theory of percolation (whether Bernoulli or Ising or other). I witnessed that this generated deep regrets from several leading probabilists.

His involvement in the new task that he assigned himself was totalizing: to study the few remnants of the Hellenistic age, he ended up gradually learning classic Greek (starting from brushing up the Latin and Greek he had learned in high school). The works that arise from this activity are for me difficult to comment on, not having really worked on the ancient or modern history of science, and I will try to mention briefly some of them; many are in Italian, and I expect that after translation into English they will generate an even wider debate.

He began, around 1990, with a critique of the authenticity of the geometric entities in the definitions at the beginning of Euclid's Elements. The analysis appeared in the Bollettino dei Classici of the Accademia dei Lincei, and a revised English version in the Archive for History of Exact Sciences [Russo 1992; 1998a]. The 
thesis is that, in the several centuries elapsed since Euclid to the present version of the Elements, the introductory definitions were added to the original work, or "simplified". The thesis is developed by a detailed logical analysis of the definitions; they are certainly captivating and lead to meditation on the subject. They are often not accepted on the grounds that some incompetent scholar should have dared to "simplify" Euclid's work [Artmann 1998]. Personally I see no reason to rule out the possibility of distortion in the transmission of the definitions: the work of Boltzmann (whose original sources are still available) is a compelling example of how scientific ideas may be misinterpreted, and nevertheless be useful, just a few years (not even centuries) after most scientists proceeded to make use of their consequences relying on expositions rather than relying on the original.

Several essays followed: with sharp critiques of modern interpretations of Hellenistic achievements in astronomy, geography, mechanics, dynamics [Russo 1993b; 1994], gravitation and tidal theory [Russo 1993a; 1993c]. In [Russo and Medaglia 1996] he convincingly refuted the common wisdom that Aristarchus was accused of "impiety" because of his heliocentric system.

His essays have often been collected and extended in books, starting with The Forgotten Revolution, whose Italian original [Russo 1996] went through three editions, was then revised as it was translated into English [Russo 2004], and from there into German and Polish. The book is captivating, with several new readings of Greek and Roman texts which are often very convincing (showing the contribution that practicing scientists can make to historical research). In the final chapters of the book, he defends the view that the development of science in the Renaissance benefited from access to ancient works that circulated in Europe after the fall of Constantinople - to a far greater extent that is usually recognized, because some of those works have since been lost. The notion that Renaissance scholars might have concealed their inspiration in ancient sources has faced skepticism or outright rejection in many quarters (see [Pambuccian 2001; Ewing 2004; Greene 2004; Rowan-Robinson 2004] for example), though others have been more open to that possibility [Graffi 1998; Netz 2002]. However controversial Russo's views on the development of modern science may be, his discussion of the classic achievements and of the imperial decay of science is fascinating and rich in new insights.

The Forgotten Revolution is a seminal and stimulating work whose theses will long generate debate and further studies. An example that illuminates the kind of critical examination of sources (here Pliny and Vitruvius) that Russo excels at considers the motion of the moon [Russo 1996, §10.6, p. 319; Russo 2004, §10.8]. He advanced this argument elsewhere as well: for instance in an essay on the astronomy of Hipparchus [Russo 1994] and other pre-Ptolemaic sources.

Russo has since written more essays, eventually coherently organized and collected into books. For instance, the book Flussi e riflussi on the history and the 
origins of the theory of tides, expanding [Russo 1995], gives a detailed and documented analysis of the developments in the modern period and its roots in antiquity [Bonelli and Russo 1996; Russo 2003], stressing that the theory was developed with apparently independent contributions repeatedly discovered and lost or forgotten, influencing many thoughts and ending to be eventually attributed only to particular scientists (Newton, Laplace, Kelvin and G. H. Darwin). And we list only a few essays: a discussion on the nature of and relation between mathematics and physics and its evolution from Hellenism to contemporary science or a paper on the "case" of Aristarchus [Russo 2002], which goes back to the impiety accusation and further clarifies its unfoundedness, shown to be due to a misunderstanding of a text of Plutarch. He discusses also the important contributions of Seleucus to heliocentrism and to theories of tides [Russo 2002] and an essay on Archimedes and on the myths about him [Russo 2013a].

A more unorthodox book is L'America dimenticata [Russo 2013b], where he develops the idea (briefly suggested in the Revolution) that America was visited over an extended period of time by sailors from the ancient Mediterranean, including the Carthaginians both before and after the downfall of their city. The book focuses on the thesis that civilization is not deterministically controlled by human genes, and independent human communities might evolve very differently rather than proceeding, deterministically, in parallel through the same stages, only up to random time delays. In particular major calamities might completely stop, pull back by centuries or divert the evolution: one of them was the Roman destruction of Carthage, which cut earlier links between Europe and Central America, as Russo contends, and caused the loss of knowledge of the Atlantic navigation practiced at least by Phoenicians and Carthaginians, with the result that scanty vestiges remain of the link between the evolution of European and American civilizations.

The case is discussed in detail, expanding [Russo 2013c], and taking the opportunity to analyze a debated geography question and to offer a new interpretation of the related work of Ptolemy. The highlight is a scientific analysis of the reduction of the Earth's circumference from 252000 to 180000 stadia: from the value established by Eratosthenes and used by Hipparchus to the value documented, more than three centuries later, by Ptolemy.

According to Russo, the problem was not, as often thought, that Ptolemy mistook the length of the "Eratosthenes stadium" (thinking it to be 1.43 times smaller than that used afterwards, well into the next millennium). Instead, the error can be traced to the misidentification of the extreme western point of the known world with the Canary Islands, rather than the Lesser Antilles.

To be precise, according to Ptolemy, the latitude of this western limit (expressed in today's coordinates) was around $5.5^{\circ}$, and it belonged to what he called the Blessed Isles. He identified them with the Canary Islands; but he states that the 
longitudinal extent of the Blessed Isles is $1^{\circ}$, while the Canaries archipelago is close to $5^{\circ}$ wide, and there is also a $15^{\circ}$ difference in latitude between the two. A better fit for the Blessed Isles of Ptolemy's sources, Russo contends, would be the Lesser Antilles, which match the latitude and longitudinal extent reported by Ptolemy, and also match the longitude deduced from other information that Ptolemy provides: that the western and eastern edges of the known world lie on opposite meridians, and that the eastern edge is at a certain (relatively short) distance from the capital of China, whole location in Hellenistic times we know (Xi'an).

Russo's conclusion and proposal is that Ptolemy, taking as given the $180^{\circ}$ width of the known world - a datum apparently inherited from earlier scientists (the evidence is analyzed) - and its eastern limit, unwittingly moved east its western limit, because the Blessed Isles had become associated with the Canary Islands, their earlier identity having been forgotten in the wake of Carthage's destruction (further arguments can be found in [Russo 2016]). A consequence seems to be that Ptolemy had several correct distances along (some) parallels but no accurate astronomical determination of longitudes for at least a few known sites ${ }^{1}$ to fit the known distances: giving the Canaries as the extreme limit and $180^{\circ}$ degrees the width of the inhabited world, a shorter Earth radius and a dilation of the longitudes resulted.

The analysis also solves another mystery arising from Ptolemy's Geography: the location of Thule. Showing that the most common accepted proposals do not fit all available facts, Russo places Thule, after reinterpreting Ptolemy's value of its longitude, on the east coast of Greenland, which is consistent with what we know of Pytheas' explorations.

The book contains a dense set of footnotes to document the statements taken from the literature (mostly classical) and a captivating analysis of them. Unfortunately the notes have been relegated to the end of the chapters (as done also in the next book by Russo, a choice increasingly made by printers), which is very inconvenient for the readers because the footnotes are really essential here.

In a third book Stelle, atomi e velieri (Stars, atoms and sailing ships) [Russo 2015], the basic idea on the nondeterministic evolution of science and its dependence on continuous interaction, through possibly tenuous temporal or spatial links between different scientists, is taken up again and further developed. Here Russo puts together all his previous arguments and offers a rapid and synthetic view of some of the major events in the history of science, always paying attention and

\footnotetext{
${ }^{1}$ Longitude could have been only determined by on-site astronomical observations, which require (good instruments and) a physical presence to observe the exact moment of an expected celestial event, e.g., a lunar eclipse or an equinox, and either the exact local solar hour or the concomitant equatorial coordinates of a star. Such observations were possible in antiquity (and positively mentioned and appreciated by Ptolemy [Russo 2013b, p. 158]) but there are few clear traces of them.
} 
adding evidence to reinforce the main idea that can be found in his earlier books and papers. For instance it is interesting to see collected and organized in a wider context the analysis of the roles of Copernicus and Bruno and the violent opinions of Voltaire on Aristarchus, which will make at least some readers wish that Voltaire had been more careful in his judgment; see also [Bonelli and Russo 1996; Russo 2002]. The book expands all themes treated earlier, adding substantial remarks on science after the Renaissance, with arguments in favor of one of his main theses, i.e., the cultural interdependence between many scientists, starting with Hellenic and Hellenistic science, and that major discoveries are often only attributed to "giants". He acutely examines the evolution of the disciplines called mathematics, physics and mathematical physics, expressing judgments which will, likely, generate lively debates.

Recently Russo has proposed a probabilistic approach to the determination of the dates of events known to have occurred in a time interval [Benedetto et al. 2016], a return to probability theory, applied to the date of birth of Hypatia and Theon. A further book is dedicated to the history of science in Italy [Russo and Santoni 2010]. The editorial activity of Russo also led him to write, perhaps under the influence of his personal history with parents deeply dedicated to high school teaching (hence with an early direct knowledge of the problems and issues), an essay on education criticizing, often harshly, the modern methods of teaching science in the Italian high schools [Russo 1998b], a critique which hopefully will be heard, sooner or later.

\section{References}

[Aizenman 1980] M. Aizenman, "Translation invariance and instability of phase coexistence in the two-dimensional Ising system”, Comm. Math. Phys. 73:1 (1980), 83-94.

[Aizenman et al. 1983] M. Aizenman, J. T. Chayes, L. Chayes, J. Fröhlich, and L. Russo, "On a sharp transition from area law to perimeter law in a system of random surfaces", Comm. Math. Phys. 92:1 (1983), 19-69.

[Artmann 1998] B. Artmann, Review of [Russo 1998a], Math Reviews, 1998, Available at http:// www.ams.org/mathscinet-getitem? $\mathrm{mr}=1612769$.

[Benedetto et al. 2016] C. Benedetto, S. Isola, and L. Russo, "Dating Hypatia's birth: a probabilistic model", preprint, 2016, Available at https://www.researchgate.net/publication/307593271. To appear in Math. Mech. Complex Syst.

[Bonelli and Russo 1996] F. Bonelli and L. Russo, "The origin of modern astronomical theories of tides: Chrisogono, de Dominis and their sources”, Brit. J. Hist. Sci. 29:4 (1996), 385-401.

[Cammarota and Russo 1991] C. Cammarota and L. Russo, "Bernoulli and Gibbs probabilities of subgroups of $\{0,1\}^{S}$, Forum Math. 3 (1991), 401-414.

[Campanino and Russo 1985] M. Campanino and L. Russo, "An upper bound on the critical percolation probability for the three-dimensional cubic lattice", Ann. Probab. 13:2 (1985), 478-491.

[Coniglio et al. 1976] A. Coniglio, C. R. Nappi, F. Peruggi, and L. Russo, "Percolation and phase transitions in the Ising model”, Comm. Math. Phys. 51:3 (1976), 315-323. 
[Coniglio et al. 1977] A. Coniglio, C. R. Nappi, F. Peruggi, and L. Russo, "Percolation points and critical point in the Ising model", J. Phys. A 10:2 (1977), 205-218.

[Ewing 2004] J. H. Ewing, Review of [Russo 2004], Math Reviews, 2004, Available at http:// www.ams.org/mathscinet-getitem?mr=2038833.

[Facchinetti and Russo 1983] G. Facchinetti and L. Russo, "A one-dimensional case of stochastic homogenization", Boll. Un. Mat. Ital. C (6) 2:1 (1983), 159-170.

[Franceschini and Russo 1981] V. Franceschini and L. Russo, "Stable and unstable manifolds of the Hénon mapping", J. Statist. Phys. 25:4 (1981), 757-769.

[Gandolfi et al. 1988a] A. Gandolfi, G. Grimmett, and L. Russo, "On the uniqueness of the infinite cluster in the percolation model”, Comm. Math. Phys. 114:4 (1988), 549-552.

[Gandolfi et al. 1988b] A. Gandolfi, M. Keane, and L. Russo, "On the uniqueness of the infinite occupied cluster in dependent two-dimensional site percolation", Ann. Probab. 16:3 (1988), 11471157.

[Graffi 1998] S. Graffi, Review of [Russo 1996], Notices Amer. Math. Soc. 45:5, 1998, Available at http://www.ams.org/notices/199805/review-graffi.pdf.

[Greene 2004] M. Greene, “The birth of modern science?”, Nature 430:7000 (2004), 614. Review of [Russo 2004].

[Higuchi 1981] Y. Higuchi, "On the absence of non-translation invariant Gibbs states for the twodimensional Ising model”, pp. 517-534 in Random fields (Esztergom, Hungary, 1979), vol. I, edited by J. Fritz et al., Colloq. Math. Soc. János Bolyai 27, North-Holland, Amsterdam, 1981.

[Keane and Smorodinsky 1977] M. Keane and M. Smorodinsky, "A class of finitary codes", Israel J. Math. 26:3-4 (1977), 352-371.

[di Liberto et al. 1973] F. di Liberto, G. Gallavotti, and L. Russo, "Markov processes, Bernoulli schemes, and Ising model", Comm. Math. Phys. 33:4 (1973), 259-282.

[Monroy and Russo 1975] G. Monroy and L. Russo, "A family of codes between some Markov and Bernoulli schemes”, Comm. Math. Phys. 43:2 (1975), 155-159.

[Netz 2002] R. Netz, "Review: La rivoluzione dimenticata. Il pensiero scientifico greco e la scienza moderna", Hist. Math. 29:1 (2002), 72-73.

[Pambuccian 2001] V. V. Pambuccian, Review of [Russo 1996], Math Reviews, 2001, Available at http://www.ams.org/mathscinet-getitem?mr=1629047.

[Rowan-Robinson 2004] M. Rowan-Robinson, "Praising Alexandrians to excess", Phys. World 17:4 (2004), 42. Review of [Russo 2004].

[Russo 1978] L. Russo, “A note on percolation”, Z. Wahrsch. Verw. Gebiete 43:1 (1978), 39-48.

[Russo 1979] L. Russo, "The infinite cluster method in the two-dimensional Ising model”, Comm. Math. Phys. 67:3 (1979), 251-266.

[Russo 1981] L. Russo, "On the critical percolation probabilities", Z. Wahrsch. Verw. Gebiete 56:2 (1981), 229-237.

[Russo 1982] L. Russo, “An approximate zero-one law”, Z. Wahrsch. Verw. Gebiete 61:1 (1982), 129-139.

[Russo 1992] L. Russo, "Sulla non autenticità delle definizioni degli enti geometrici fondamentali contenute negli Elementi di Euclide", Boll. Classici 13 (1992), 25-44.

[Russo 1993a] L. Russo, "Il contenuto scientifico di un brano di Lucrezio (IV, 387-396)", Boll. Classici 14 (1993), 93-95.

[Russo 1993b] L. Russo, "Un brano di Plutarco (Moralia, 923C-924A) e la storia della dinamica", Boll. Classici 14 (1993), 80-92. 
[Russo 1993c] L. Russo, "Vitruvio ('De architectura', IX, i, 11-14): un brano di argomento astronomico”, Boll. Classici 14 (1993), 96-102.

[Russo 1994] L. Russo, "The astronomy of Hipparchus and his time: a study based on pre-Ptolemaic sources", Vistas Astronom. 38:2 (1994), 207-248.

[Russo 1995] L. Russo, "L'astronomo Seleuco, Galileo e la teoria della gravitazione", Quaderni Urbinati Cultura Classica 49:1 (1995), 143-160.

[Russo 1996] L. Russo, La rivoluzione dimenticata: il pensiero scientifico greco e la scienza moderna, Feltrinelli, Milan, 1996.

[Russo 1998a] L. Russo, "The definitions of fundamental geometric entities contained in Book I of Euclid's Elements”, Arch. Hist. Exact Sci. 52:3 (1998), 195-219.

[Russo 1998b] L. Russo, Segmenti e bastoncini: dove sta andando la scuola?, Feltrinelli, Milan, 1998.

[Russo 2002] L. Russo, "Aristarco di Samo: uno scienzato isolato?", preprint, 2002, Available at http://www.academia.edu/5791148.

[Russo 2003] L. Russo, Flussi e riflussi: indagine sull'origine di una teoria scientifica, Feltrinelli, Milan, 2003.

[Russo 2004] L. Russo, The forgotten revolution: how science was born in 300 BC and why it had to be reborn, Springer, 2004.

[Russo 2013a] L. Russo, "Archimedes between legend and fact", Lettera Mat. 1:3 (2013), 91-95.

[Russo 2013b] L. Russo, L'America dimenticata: i rapporti tra le civiltà e un errore di Tolomeo, Mondadori Università, Milan, 2013.

[Russo 2013c] L. Russo, “Ptolemy's longitudes and Eratosthenes' measurement of the earth's circumference”, Math. Mech. Complex Syst. 1:1 (2013), 67-79.

[Russo 2015] L. Russo, Stelle, atomi e velieri: percorsi di storia della scienza, Mondadori Università, Milan, 2015.

[Russo 2016] L. Russo, "Far-reaching Hellenistic geographical knowledge hidden in Ptolemy's data”, preprint, 2016, Available at https://hal.archives-ouvertes.fr/hal-01275282.

[Russo and Medaglia 1996] L. Russo and S. M. Medaglia, "Sulla presunta accusa di empietà ad Aristarco di Samo", Quaderni Urbinati Cultura Classica 53:2 (1996), 113-121.

[Russo and Santoni 2010] L. Russo and E. Santoni, Ingegni minuti: una storia della scienza in Italia, Feltrinelli, Milan, 2010.

Received 7 Nov 2016. Accepted 19 Dec 2016.

GIOVANNI GALLAVOTTI: giovanni.gallavotti@roma1.infn.it

Dipartimento di Fisica, Universitá di Roma "La Sapienza”, 00185 Roma, Italy 
EDITORIAL BOARD

ANTONIO CARCATERRA

ERIC A. CARLEN

FRANCESCO DELL'ISOLA

RAFFAELE ESPOSITO

ALBERT FANNJIANG

Gilles A. FranCFORT

Pierangelo MARCATI

JEAN-JACQUES MARIGO

PETER A. MARKOWICH

MARTIN OSTOJA-STARZEWSKI

PIERRE SEPPECHER

DAVID J. STEIGMANN

PAUl STEINMANN

PierRe M. SuQueT

MANAGING EDITORS

MICOL AMAR

CORRADO LATTANZIO

ANGELA MADEO

MARTIN OSTOJA-STARZEWSKI

ADVISORY BOARD

ADNAN AKAY

Holm AltenBaCH

MICOL AMAR

HARM ASKES

TEODOR ATANACKOVIĆ

VICTOR BERDICHEVSKY

GUY BOUCHITTÉ

ANDREA BRAIDES

ROBERTO CAMASSA

MAURO CARFORE

ERIC DARVE

FELIX DARVE

ANNA DE MASI

GianPiEtro DEL Piero

EMMANUELE Di BENEDETTO

BERNOLD FIEDLER

IRENE M. GAMBA

DAVID Y. GAO

SERGEY GAVRILYUK

TIMOTHY J. HEALEY

DOMINIQUE JEULIN

ROGER E. KHAYAT

CORRADO LATTANZIO

ROBERT P. LIPTON

ANGELO LUONGO

ANGELA MADEO

JUAN J. MANFREDI

CARLO MARCHIORO

GÉRARD A. MAUGIN

ROBERTO NATALINI PATRIZIO NEFF

ANDREY PIATNITSKI

ERRICO PRESUTTI

MARIO PULVIRENTI

LUCIO RUSSO

Miguel A. F. SANJUAN

PATRICK SElVADURAI

ALEXANDER P. SEYRANIAN

MIROSLAV ŠILHAVÝ

GUIDO SWEERS

ANTOINETTE TORDESILLAS

LEV TRUSKINOVSKY

JUAN J. L. VELÁZQUEZ VINCENZO VESPRI ANGELO VULPIANI msp.org/memocs

Università di Roma "La Sapienza", Italia

Rutgers University, USA

(CO-CHAIR) Università di Roma "La Sapienza", Italia

(TREASURER) Università dell'Aquila, Italia

University of California at Davis, USA

(CO-CHAIR) Université Paris-Nord, France

Università dell'Aquila, Italy

École Polytechnique, France

DAMTP Cambridge, UK, and University of Vienna, Austria

(CHAIR MANAGING EDITOR) Univ. of Illinois at Urbana-Champaign, USA

Université du Sud Toulon-Var, France

University of California at Berkeley, USA

Universität Erlangen-Nürnberg, Germany

LMA CNRS Marseille, France

Università di Roma "La Sapienza", Italia

Università dell'Aquila, Italy

Université de Lyon-INSA (Institut National des Sciences Appliquées), France

(CHAIR MANAGING EDITOR) Univ. of Illinois at Urbana-Champaign, USA

Carnegie Mellon University, USA, and Bilkent University, Turkey

Otto-von-Guericke-Universität Magdeburg, Germany

Università di Roma "La Sapienza", Italia

University of Sheffield, UK

University of Novi Sad, Serbia

Wayne State University, USA

Université du Sud Toulon-Var, France

Università di Roma Tor Vergata, Italia

University of North Carolina at Chapel Hill, USA

Università di Pavia, Italia

Stanford University, USA

Institut Polytechnique de Grenoble, France

Università dell'Aquila, Italia

Università di Ferrara and International Research Center MEMOCS, Italia

Vanderbilt University, USA

Freie Universität Berlin, Germany

University of Texas at Austin, USA

Federation University and Australian National University, Australia

Université Aix-Marseille, France

Cornell University, USA

École des Mines, France

University of Western Ontario, Canada

Università dell' Aquila, Italy

Louisiana State University, USA

Università dell'Aquila, Italia

Université de Lyon-INSA (Institut National des Sciences Appliquées), France University of Pittsburgh, USA

Università di Roma "La Sapienza”, Italia

Université Paris VI, France

Istituto per le Applicazioni del Calcolo "M. Picone", Italy

Universität Duisburg-Essen, Germany

Narvik University College, Norway, Russia

Università di Roma Tor Vergata, Italy

Università di Roma "La Sapienza”, Italia

Università di Roma “Tor Vergata”, Italia

Universidad Rey Juan Carlos, Madrid, Spain

McGill University, Canada

Moscow State Lomonosov University, Russia

Academy of Sciences of the Czech Republic

Universität zu Köln, Germany

University of Melbourne, Australia

École Polytechnique, France

Bonn University, Germany

Università di Firenze, Italia

Università di Roma La Sapienza, Italia

MEMOCS (ISSN 2325-3444 electronic, 2326-7186 printed) is a journal of the International Research Center for the Mathematics and Mechanics of Complex Systems at the Università dell'Aquila, Italy.

Cover image: "Tangle” by $\odot$ John Horigan; produced using the Context Free program (contextfreeart.org).

PUBLISHED BY

7 mathematical sciences publishers

nonprofit scientific publishing

http://msp.org/

(C) 2016 Mathematical Sciences Publishers 
Special issue in honor of

Lucio Russo

Lucio Russo: A multifaceted life

Raffaele Esposito and Francesco dell'Isola

The work of Lucio Russo on percolation Geoffrey R. Grimmett

"Mathematics" and "physics" in the science of harmonics Stefano Isola

From quantum to classical world: emergence of trajectories in a quantum system Rodolfo Figari and Alessandro Teta

Propagation of chaos and effective equations in kinetic theory: a brief survey Mario Pulvirenti and Sergio Simonella

What decides the direction of a current? Christian Maes

A remark on eigenvalue perturbation theory at vanishing isolation distance Fiorella Barone and Sandro Graffi

Some results on the asymptotic behavior of finite connection probabilities in percolation Massimo Campanino and Michele Gianfelice

Correlation inequalities for the Potts model Geoffrey R. Grimmett

Quantum mechanics: some basic techniques for some basic models, I: The models Vincenzo Grecchi

Quantum mechanics: some basic techniques for some basic models, II: The techniques Vincenzo Grecchi

On stochastic distributions and currents

Vincenzo Capasso and Franco Flandoli

A note on Gibbs and Markov random fields with constraints and their moments Alberto Gandolfi and Pietro Lenarda

Quantum mechanics: light and shadows (ontological problems and epistemic solutions) Gianfausto Dell'Antonio

MEMOCS is a journal of the International Research Center for the Mathematics and Mechanics of Complex Systems at the Università dell' Aquila, Italy.

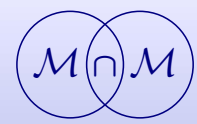

